\title{
Emotional abuse among children: a study in Jeddah, Saudi Arabia
}

W. Elarousy ${ }^{1,2}$ and M. Al-Jadaani

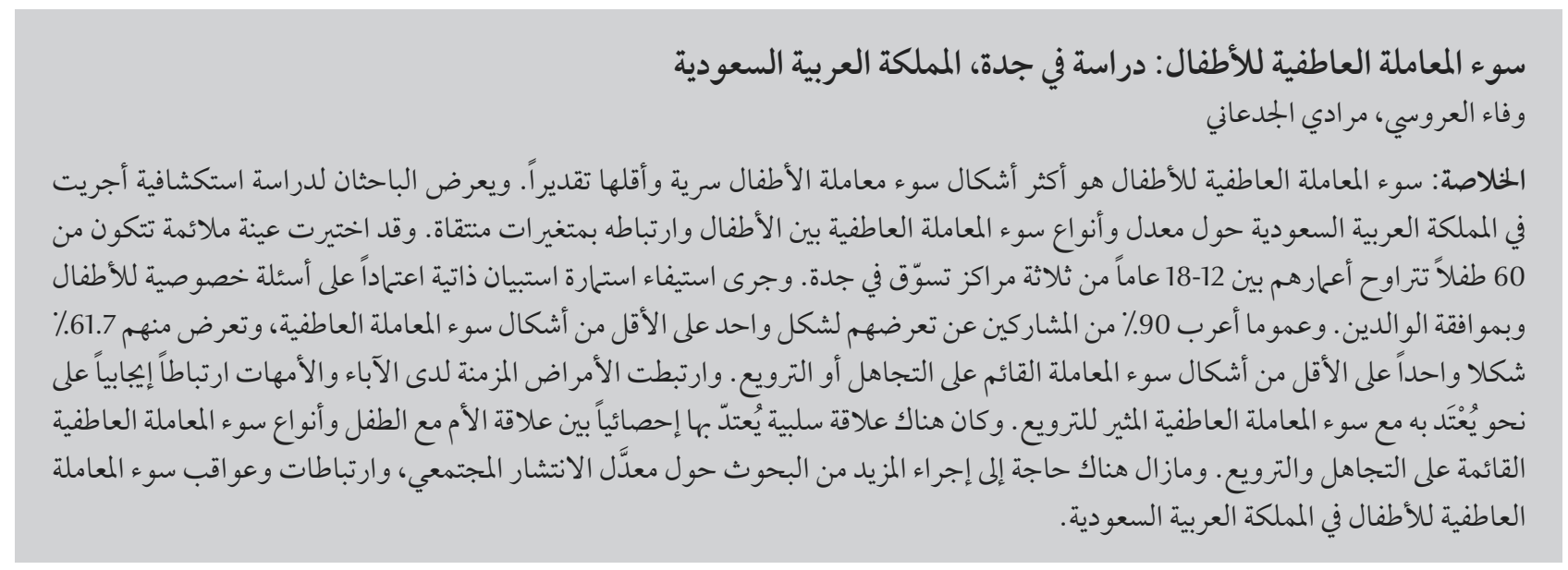

ABSTRACT Emotional abuse is the most hidden and underestimated form of child maltreatment. We report an exploratory study in Saudi Arabia of the rate and types of emotional abuse among children and its association with selected variables. A convenience sample of 60 children aged 12-18 years was recruited from 3 malls in Jeddah. A specially designed, self-administered questionnaire was completed in confidence by the children with the consent of parents. Overall $90 \%$ of participants reported at least 1 form of rejecting emotional abuse and $61.7 \%$ at least 1 form of ignoring or terrorizing types of abuse. Chronic illness among parents was significantly positively correlated with terrorizing emotional abuse. There was a statistically significant negative correlation between mothers' relationship with the child and ignoring and terrorizing types of emotional abuse. Further research is needed about the community prevalence, correlates and consequences of child emotional abuse in Saudi Arabia.

\section{Violence psychologique chez l'enfant : une étude à Djeddah (Arabie saoudite)}

RÉSUMÉ La violence psychologique est la forme la plus sous-estimée et cachée de maltraitance chez l'enfant. Nous présentons une étude exploratoire en Arabie saoudite, portant sur les taux et les types de violence psychologique chez l'enfant et son association à des variables sélectionnées. Un échantillon de commodité de 60 enfants âgés de 12 à 18 ans a été recruté dans trois centres commerciaux de Djeddah. Un questionnaire auto-administré spécialement conçu a été rempli de manière confidentielle par les enfants avec le consentement de leurs parents. Globalement, $90 \%$ des participants ont déclaré avoir souffert d'au moins une forme de violence psychologique par le rejet et $61,7 \%$ d'au moins une forme de mauvais traitements impliquant la négligence ou la terreur à leur encontre. Une maladie chronique des parents était significativement et positivement corrélée à la violence psychologique exercée par la terreur. Une corrélation négative statistiquement significative a été observée entre la relation de la mère avec son enfant et les types de violence psychologique impliquant le rejet et la terreur. Des recherches plus approfondies sont requises sur la prévalence dans la communauté, les corrélations et les conséquences de la violence psychologique chez l'enfant en Arabie Saoudite.

${ }^{7}$ College of Nursing, King Saud Bin Abdulaziz University for Health Science, Jeddah, Saudi Arabia (Correspondence to W. El-Arousy: wafaaelarousy@hotmail.com).

${ }^{2}$ Faculty of Nursing, University of Alexandria, Alexandria, Egypt.

Received: 20/05/12; accepted: 25/06/12 


\section{Introduction}

Every child has the right to health and a life free from violence. Each year, though, millions of children around the world are the victims and witnesses of physical, sexual and emotional violence [1]. Emotional abuse does not leave physical injuries and its ongoing nature usually means there is no crisis that would precipitate its identification by the health, welfare or criminal justice systems. For that reason emotional abuse is the most hidden and underestimated form of child maltreatment [2]. The consequences of child emotional abuse can be devastating and long-lasting and include increased risk for a lifelong pattern of depression, anxiety, low self-esteem, inappropriate or troubled relationships or a lack of empathy [3]. The consequences of children abuse are affected by many variables including: the nature, frequency, intensity and duration of abuse [4].Studies conducted in the Arab Peninsula revealed that children there are subjected to all forms of child maltreatment. Child abuse is ignored or may even be tolerated and accepted as a form of discipline [5].

Emotional and psychological abuse involves both isolated incidents, as well as a pattern of failure over time on the part of a parent or caregiver to provide a developmentally appropriate and supportive environment. Acts in this category may have a high probability of damaging the child's physical or mental health, spiritual, moral or social development. Abuse of this type includes: the restriction of movement; patterns of belittling, blaming, threatening, frightening, discriminating against or ridiculing; and other non-physical forms of rejection or hostile treatment [2]. Rejecting, ignoring and terrorizing are types of emotional abuse. Rejecting means putting down a child or youth's worth or putting down their needs. Ignoring is failing to give any response to or interact with a child or youth at all. Terrorizing is defined as causing a child or youth to be terrified by the constant use of threats and/or intimidating behaviour $[6,7]$.

Research efforts to gain a clear understanding of the origins, nature and risk factors of child emotional abuse are needed. An increased understanding of child emotional abuse is essential before practitioners and policy-makers can begin crafting policy and interventions aimed at addressing child emotional abuse. We report an exploratory study in Saudi Arabia of the level of emotional abuse among a convenience sample of children from malls, to describe the forms of rejecting, ignoring and terrorizing emotional abuse reported by the children and to describe the association between the forms of emotional abuse and selected variables.

\section{Methods}

\section{Study design and sample}

A descriptive, correlational study design was used [8]. A convenience sample of 60 children were recruited over the 2 months from December 2011 to January 2012 from among families visiting 3 different malls in Jeddah, Saudi Arabia. These malls are among the largest malls in Jeddah and are visited by all different social groups. The inclusion criteria: were male and female children aged $12-18$ years who were willing to participate in the study and whose guardians agreed to the child participating. The exclusion criteria were children and their guardians who refused to participate in the study. A total of 100 families were approached but 40 families refused after reading the questionnaire.

\section{Data collection}

The questionnaire was developed by the researchers, after a review of the literature. It included 2 parts: demographic data of the child and parents (age, sex, education level) and questions about the forms of emotional abuse. The questions were in the form of statements that reflect rejecting, ignoring and terrorizing types of emotional abuse and the participants responded to each statement by 4 options: usually, sometimes, rarely or never. A pilot study was done by asking 10 children to complete the questionnaire and any necessary modifications were made to the questionnaire. The validity of the questionnaire was determined by asking experts to assess the relevance to and coverage of the topic and necessary modifications were done. Test of reliability showed a Cronbach alpha of 0.78 , which is acceptable according to Burn and Grove [9].

The researcher visited the malls at weekends (Thursday and Friday) and introduced herself and the purposes of the study to available children and their guardians in the mall. The researcher distributed a self-administered questionnaire to those participants who were willing to participate, after asking their guardians to sign the informed consent. The form was filled by the child on another table away from the parents in the same food court. To minimize the possibility of bias the researchers ensured that data collection was standardized and that the respondents received standardized instructions on how to complete the questionnaires.

The information of the current study was handled confidentially. All identifying information obtained was coded and kept in a locked file and no one had access to the data except the researchers. Data was presented in aggregated format so that participants' identification was secured. Children's guardians signed a consent form for them to participate in the study after learning that participation was voluntary. No other ethical issues were 
of concern. The study was approved by the College of Nursing research committee.

\section{Statistical analysis}

Statistical analysis was carried out using SPSS, version 18.0 software. The data were illustrated using simple descriptive statistics and cross-tabulations. The chi-squared test was used to compare differences and the Pearson test was used for correlations. $P$-value $<0.05$ was considered statistically significant.

\section{Results}

Table 1 illustrates the demographic characteristics of the children. Their ages ranged from 13 to 18 years with mean age of 16.0 (SD 1.6) years; $38.3 \%$ of the children were males while $61.7 \%$ were females. All of them were Saudi nationals. One-quarter $(25.0 \%)$ of mothers and $38.3 \%$ of fathers had university education, while $5.0 \%$ of mothers and $6.7 \%$ of fathers were illiterate. One-third of mothers (33.3\%) had a job, and the remaining two-thirds were housewives, while $85.0 \%$ of fathers had a job and $15.0 \%$ were not working. A chronic disease was reported by $53.3 \%$ of parents.

Table 2 presents the childrenparent relationships, as reported by children on a scale that ranged from strong to bad relationship. A strong relationship with the mother was reported by $73.3 \%$ of children and with the father by $53.3 \%$, while a weak relationship was reported with the mother by $18.3 \%$ and with the father by $25.0 \%$. No relationship (neither good nor bad) was reported by $6.7 \%$ of children for the mother and $16.7 \%$ of for the father. A few children described their relationship with their mother and father as bad (1.7\% and 5.0\% respectively).

Table 3 illustrates the percentage distribution of children according to

\begin{tabular}{|c|c|c|}
\hline Characteristic & No. & $\%$ \\
\hline \multicolumn{3}{|l|}{ Age (years) } \\
\hline $13-15$ & 23 & 38.3 \\
\hline $16-18$ & 37 & 61.7 \\
\hline \multicolumn{3}{|l|}{ Sex } \\
\hline Male & 23 & 38.3 \\
\hline Female & 37 & 61.7 \\
\hline \multicolumn{3}{|c|}{ Educational level of mother } \\
\hline Illiterate & 3 & 5.0 \\
\hline Elementary & 10 & 16.7 \\
\hline Intermediate & 10 & 16.7 \\
\hline High school & 22 & 36.7 \\
\hline University & 15 & 25.0 \\
\hline \multicolumn{3}{|c|}{ Educational level offather } \\
\hline Illiterate & 4 & 6.7 \\
\hline Elementary & 15 & 25.0 \\
\hline Intermediate & 6 & 10.0 \\
\hline High school & 12 & 20.0 \\
\hline University & 23 & 38.3 \\
\hline \multicolumn{3}{|c|}{ Occupation of mother } \\
\hline Working & 20 & 33.3 \\
\hline Housewife & 40 & 66.7 \\
\hline \multicolumn{3}{|c|}{ Occupation offather } \\
\hline Working & 51 & 85.0 \\
\hline Not working & 9 & 15.0 \\
\hline \multicolumn{3}{|c|}{ Chronic disease of mother or father } \\
\hline Yes & 32 & 53.3 \\
\hline No & 28 & 46.7 \\
\hline
\end{tabular}

types of emotional abuse. It was found that $90.0 \%$ of children reported at least one form of rejecting emotional abuse while $61.7 \%$ reported at least one form

of ignoring or terrorizing type of emotional abuse.

Table 4 illustrates the percentage distribution of children according to

\begin{tabular}{|c|c|c|}
\hline Parent-child relationship & No. & $\%$ \\
\hline \multicolumn{3}{|l|}{ Relationship with mother } \\
\hline Strong & 44 & 73.3 \\
\hline Weak & 11 & 18.3 \\
\hline None & 4 & 6.7 \\
\hline Bad & 1 & 1.7 \\
\hline \multicolumn{3}{|l|}{ Relationship with the father } \\
\hline Strong & 32 & 53.3 \\
\hline Weak & 15 & 25.0 \\
\hline None & 10 & 16.7 \\
\hline Bad & 3 & 5.0 \\
\hline
\end{tabular}




\begin{tabular}{lcccc}
\hline Table 3 Percentage distribution of children according to major types of emotional abuse ever experienced $(\boldsymbol{n}=\mathbf{6 0})$ \\
\hline Types of emotional abuse & \multicolumn{2}{c}{ Yes } & \multicolumn{2}{c}{ No } \\
& No. & $\%$ & No. & 10.0 \\
Rejecting emotional abuse & 54 & 90.0 & 6 & 38.3 \\
Ignoring emotional abuse & 37 & 61.7 & 23 & 38.3 \\
Terrorizing emotional abuse & 37 & 61.7 & 23 & \\
\hline
\end{tabular}

types of emotional abuse. Among the followed by usually "treating me as items covering rejecting type of emo- a child" reported by $21.7 \%$. Usutional abuse, usually "yelling at me" ally "criticizing me" was reported by was reported by $26.7 \%$ of children $16.7 \%$ and sometimes "criticizing me" reported by $43.3 \%$ while only 1 child reported usually "telling me, I am ugly". In regards to ignoring type of abuse, usually "failing to pay attention to my

\begin{tabular}{|c|c|c|c|c|c|c|c|c|}
\hline \multirow[t]{2}{*}{ Types of emotional abuse } & \multicolumn{2}{|c|}{ Usually } & \multicolumn{2}{|c|}{ Sometimes } & \multicolumn{2}{|c|}{ Rarely } & \multicolumn{2}{|c|}{ Never } \\
\hline & No. & $\%$ & No. & $\%$ & No. & $\%$ & No. & $\%$ \\
\hline \multicolumn{9}{|l|}{ Rejecting emotional abuse } \\
\hline Yelling at child & 16 & 26.7 & 20 & 33.3 & 20 & 33.3 & 4 & 6.7 \\
\hline Treating an adolescent like he/she is a child & 13 & 21.7 & 9 & 15.0 & 12 & 20.0 & 26 & 43.3 \\
\hline Constant criticism & 10 & 16.7 & 26 & 43.3 & 20 & 33.3 & 4 & 6.7 \\
\hline $\begin{array}{l}\text { Frequent belittling and use of labels such as "stupid" } \\
\text { or "idiot" }\end{array}$ & 9 & 15.0 & 8 & 13.3 & 17 & 28.3 & 26 & 43.3 \\
\hline Refusing hugs and loving gestures & 7 & 11.7 & 6 & 10.0 & 11 & 18.3 & 36 & 60.0 \\
\hline $\begin{array}{l}\text { Not allowing child to make his/her own reasonable } \\
\text { choices }\end{array}$ & 6 & 10.0 & 7 & 11.7 & 7 & 11.7 & 39 & 65.0 \\
\hline $\begin{array}{l}\text { Constant teasing about child's body type and/or } \\
\text { weight }\end{array}$ & 3 & 5.0 & 7 & 11.7 & 15 & 25.0 & 35 & 58.3 \\
\hline Constant demeaning jokes & 3 & 5.0 & 9 & 15.0 & 8 & 13.3 & 40 & 66.7 \\
\hline Expressing regret child wasn't born the opposite sex & 3 & 5.0 & 2 & 3.3 & 8 & 13.3 & 47 & 78.3 \\
\hline Telling child he/she is ugly & 1 & 1.7 & 2 & 3.3 & 6 & 10.0 & 50 & 83.3 \\
\hline \multicolumn{9}{|l|}{ Ignoring emotional abuse } \\
\hline $\begin{array}{l}\text { Failing to pay attention to significant events in child's } \\
\text { life }\end{array}$ & 16 & 26.7 & 14 & 23.3 & 13 & 21.7 & 17 & 28.3 \\
\hline Lack of attention to schooling, peers, etc. & 14 & 23.3 & 8 & 13.3 & 13 & 21.7 & 25 & 41.7 \\
\hline Failing to engage child in family activities & 10 & 16.7 & 8 & 13.3 & 12 & 20.0 & 30 & 50.0 \\
\hline Ignoring child & 4 & 6.7 & 11 & 18.3 & 10 & 16.7 & 35 & 58.3 \\
\hline Neglecting child & 5 & 8.3 & 9 & 15.0 & 17 & 28.3 & 29 & 48.3 \\
\hline Denying child required health care & 1 & 1.7 & 1 & 1.7 & 6 & 10.0 & 52 & 86.7 \\
\hline \multicolumn{9}{|l|}{ Terrorizing emotional abuse } \\
\hline Father hits mother in front of child & 13 & 21.7 & 5 & 8.3 & 7 & 11.7 & 35 & 58.3 \\
\hline Yelling, cursing and scaring child & 11 & 18.3 & 7 & 11.7 & 17 & 28.3 & 25 & 41.7 \\
\hline Threats to abuse child physically & 10 & 16.7 & 8 & 13.3 & 11 & 18.3 & 31 & 51.7 \\
\hline Destroys a favourite object & 9 & 15.0 & 5 & 8.3 & 8 & 13.3 & 38 & 63.3 \\
\hline Threats to destroy a favourite object & 7 & 11.7 & 3 & 5.0 & 10 & 16.7 & 40 & 66.7 \\
\hline Father yells at mother a front of child & 7 & 11.7 & 3 & 5.0 & 4 & 6.7 & 46 & 76.7 \\
\hline Ridiculing child in public & 6 & 10.0 & 4 & 6.7 & 12 & 20.0 & 38 & 63.3 \\
\hline Threats to kick child out of the house & 5 & 8.3 & 1 & 1.7 & 7 & 11.7 & 47 & 78.3 \\
\hline Threats to reveal intensely embarrassing traits to peers & 4 & 6.7 & 3 & 5.0 & 4 & 6.7 & 49 & 81.7 \\
\hline Threats to cut allowance & 3 & 5.0 & 3 & 5.0 & 9 & 15.0 & 45 & 75.0 \\
\hline
\end{tabular}


significant events" was reported by $26.7 \%$ followed by "lack of attention to schooling, peers" which was reported by $23.3 \%$, while only 1 child reported "denying me required health care". Among the items for terrorizing type of emotional abuse, usually "hits my mother in front of me" was reported by $21.7 \%$ of children followed by usually "yelling, cursing and scaring me" by $18.3 \%$ of them.

More than half of the children aged $16+$ years old reported at least one form of rejecting, ignoring or terrorizing emotional abuse. The differences according to the child's age were statistically significant for rejecting and terrorizing types of emotional abuse. Slightly more females reported the 3 types of emotional abuse than did males but the difference between the sexes was not statistically significant (Table 5).

The Pearson correlation coefficients between parents' demographic characteristics and children emotional abuse were calculated (Table 6). It was found that chronic illness was positively correlated with terrorizing emotional abuse and the correlation was statistically significant $(r=0.43$, $P<0.01$ ). Mothers' relationship with the child was negatively correlated with ignoring and terrorizing emotional abuse and the correlation was statistically significant for both these types of emotional abuse $(r=-0.35, P$
$<0.01$ and $r=-0.29, P<0.05$ respectively).

\section{Discussion}

Emotional abuse is maltreatment that causes or could cause emotional, behavioural, cognitive or mental disorders [10]. It is a difficult category of maltreatment to document because often it does not involve a specific incident or visible injury. The effects of emotional maltreatment tend to become apparent over time, e.g. impaired cognitive, social and emotional development. This form of abuse may occur with or without physical abuse, but there is often an overlap [11].

In the Canadian incidence study of reported child abuse and neglect over 700 child welfare service providers reported that the incidence of emotional abuse alone in investigated maltreatment children was $15 \%$ and of emotional abuse with other types of maltreatment was 16\% [11]. In Saudi Arabia, a total of 292 child abuse cases have been registered by the National Family Safety Program; children neglect constituted $41.3 \%$ of cases and $27 \%$ of neglected children were emotionally abused [12]. In the current study, it was found that about $90 \%$ of children reported at least one form of rejecting emotional abuse and $61.7 \%$ of children reported at least one form of either ignoring or terrorizing emotional abuse. This is because emotional abuse is the most hidden and underestimated form of child maltreatment. In addition, the previous estimate in Saudi Arabia was based on registered maltreated children. Barlow and MacMillon reported that registered cases of emotional abuse represented just the tip of the iceberg, and that children under child protection comprised only a small proportion of the total number of children actually experiencing abuse of this type [13].

Nguyen and Dunne, studying types of child maltreatment and adolescent mental health, revealed that nearly all children reported having been "yelled at" and having had someone "try to make them feel guilty" [14] compared with the current study in which "yelling at me" was reported by $26.7 \%$ of the children.

A retrospective study of cases registered at the Suspected Child Abuse and Neglect (SCAN) programme in Saudi Arabia from 2000-08 reported that $53.4 \%$ of cases were males and $46.6 \%$ females, regardless the type of maltreatment [15]. A study in Viet Nam in 2009 revealed that females reported more neglect and emotional abuse than males [14]. This is in agreement with the results of the current study as females reported more emotional abuse than males, whether rejecting, ignoring or terrorizing emotional abuse.

\begin{tabular}{|c|c|c|c|c|c|c|c|c|c|c|c|c|}
\hline \multirow[t]{3}{*}{ Variable } & \multicolumn{4}{|c|}{ Rejecting } & \multicolumn{4}{|c|}{ Ignoring } & \multicolumn{4}{|c|}{ Terrorizing } \\
\hline & \multicolumn{2}{|c|}{ Yes } & \multicolumn{2}{|c|}{ No } & \multicolumn{2}{|c|}{ Yes } & \multicolumn{2}{|c|}{ No } & \multicolumn{2}{|c|}{ Yes } & \multicolumn{2}{|c|}{ No } \\
\hline & No. & $\%$ & No. & $\%$ & No. & $\%$ & No. & $\%$ & No. & $\%$ & No. & $\%$ \\
\hline \multicolumn{13}{|c|}{ Child's age (years) } \\
\hline $13-15$ & 23 & 42.6 & 0 & 0.0 & 17 & 45.9 & 6 & 26.1 & 18 & 48.6 & 5 & 21.7 \\
\hline \multirow[t]{2}{*}{$16-18$} & 31 & 57.4 & 6 & 100.0 & 20 & 54.1 & 17 & 73.9 & 19 & 54.1 & 18 & 78.3 \\
\hline & \multicolumn{4}{|c|}{$\chi^{2}=4.14, P=0.042$} & \multicolumn{4}{|c|}{$\chi^{2}=2.37, P=0.124$} & \multicolumn{4}{|c|}{$\chi^{2}=4.35, P=0.037$} \\
\hline \multicolumn{13}{|l|}{ Sex } \\
\hline Male & 21 & 38.9 & 2 & 33.3 & 17 & 45.9 & 6 & 26.1 & 16 & 43.2 & 7 & 30.4 \\
\hline \multirow[t]{2}{*}{ Female } & 33 & 61.1 & 4 & 66.7 & 20 & 54.1 & 17 & 73.9 & 21 & 56.8 & 16 & 43.2 \\
\hline & \multicolumn{4}{|c|}{$\chi^{2}=0.07, P=0.791$} & \multicolumn{4}{|c|}{$\chi^{2}=2.37, P=0.124$} & \multicolumn{4}{|c|}{$\chi^{2}=0.98, P=0.321$} \\
\hline
\end{tabular}




\begin{tabular}{|c|c|c|c|}
\hline \multirow[t]{2}{*}{ Parent's demographic characteristics } & \multicolumn{3}{|c|}{ Correlation coefficient } \\
\hline & Rejecting & Ignoring & Terrorizing \\
\hline Mother's education & -0.171 & 0.181 & 0.006 \\
\hline Father's education & 0.181 & 0.238 & 0.039 \\
\hline Mother's occupation & 0.118 & -0.242 & -0.097 \\
\hline Father's occupation & -0.140 & -0.235 & -0.139 \\
\hline Presence of chronic disease & 0.245 & 0.224 & $0.431^{* *}$ \\
\hline Mother relationship with child & -0.186 & $-0.351^{* *}$ & $-0.292^{*}$ \\
\hline Father relationship with child & -0.004 & -0.065 & -0.228 \\
\hline
\end{tabular}

${ }^{*} P<0.05 ;{ }^{*} P<0.01$.

Morrison et al. reported that children who are abused and neglected by caregivers often do not form secure attachments to them. These early attachment difficulties can lead to later difficulties in relationships with other adults as well as with peers [16]. Furthermore lack of parent-child attachment and failure to bond is associated with an increased risk of child maltreatment [2]. This is in agreement with the results of the current study, in which mothers' relationship with their children was negatively correlated with ignoring and terrorizing types of emotional abuse and the correlation was statistically significant for these 2 types of emotional abuse.

The World Health Organization reported many risk factors that increase the incidence of child abuse and neglect, such as poverty, unemployment, lack of parental education, young maternal age, substance abusing parents, parents who were abused as children and parents with psychological diagnoses [2]. In the current study, we did not find a significant correlation between parents' education and occupation with types of emotional abuse. This is may be due to the small sample size.

The United States Centers for Disease Control and Prevention reported that abuse and neglect can occur in families where there is a great deal of stress. The stress can result from many causes, including chronic health problems. Families that do not have nearby friends, relatives and other social support are also at risk [17]. Furthermore, Trocmé et al. found that at least 1 caregiver was known to have a chronic illness in $9 \%$ of children with emotional abuse [11]. This is in accordance with the results of the current study, which revealed that chronic illness among parents was significantly positively correlated with terrorizing emotional abuse.

Among the limitations of the study was refusal by many parents to participate in the study after reading the questionnaire, even to the extent of becoming angry, and this will have affected the study sample as those who are most likely to be abusers were more likely to refuse to participate.
Therefore a more comprehensive study is needed.

\section{Conclusions}

The study revealed that $90 \%$ of children who participated in the study reported at least one form of rejecting emotional abuse and $61.7 \%$ of children reported at least one form of either ignoring or terrorizing emotional abuse. There was a negative relation between mothers' education and occupation and children's experience of emotional abuse. Chronic illness was positively correlated with terrorizing emotional abuse and the correlation was statistically significant. Mothers' relationship with the child was negatively correlated with the ignoring and terrorizing types of children emotional abuse and the correlation was statistically significant for ignoring and terrorizing emotional abuse. More research is needed into the community prevalence, correlates and consequences of children emotional abuse in Saudi Arabia.

Competing interests: None declared

\section{References}

1. McDonald KC. Child abuse: approach and management. American Family Physician, 2007, 75:221-228.

2. Preventing child maltreatment: a guide to taking action and generating evidence. Geneva, World Health Organization, 2006.
3. Prevent Child Abuse America [website] (www.preventchildabuse.org, accessed 23 June 2013).

4. Iwaniec D, Larkin E, Higgins S. Research Review: Risk and resilience in cases of emotional abuse. Child and Family Social Work, 2006, 11:73-82. 
5. Al-Mahroos FT. Child abuse and neglect in the Arab Peninsula. Saudi Medical Journal, 2007, 28:241-248.

6. Kairys SW, Johnson CF; Committee on Child Abuse and Neglect. The psychological maltreatment of children-technical report. Pediatrics, 2002, 109:e68.

7. Straus M, Field C. Psychological aggression by American parents: National data on prevalence, chronicity and severity. Washington DC, American Sociological Association, 2000.

8. Lo Biondo-Wood G, Haber J. Nursing research: methods and critical appraisal for evidence-based practice, 7th ed. St Louis, Missouri, Mosby Elsevier, 2010.

9. Burn N, Grove SK. The practice of nursing research: conduct, critique and utilization, 5th ed. Philadelphia, Pennsylvania, WB Saunders, 2005.

10. Giardino E, Giardino A. Nursing approach to the evaluation of child maltreatment. St Louis, Missouri, GW Medical Publishing, 2003.

11. Trocmé $\mathrm{N}$ et al. Canadian incidence study of reported child abuse and neglect. Final report. Ottawa, Ontario, Health Canada, 2001.
12. National Family Safety Registry. Annual report 2010. Riyadh, Saudi Arabia, NFSR, 2010.

13. Barlow J, MacMillon A. Safeguarding children from emotional abuse-what works? Warwick, England, University of Warwick, Department for Children, Schools and Families, 2009.

14. Nguyen HT, Dunne MP, Le AV. Multiple types of child maltreatment and adolescent mental health in Viet Nam. Bulletin of the World Health Organization, 2010, 88:22-30.

15. Al Eissa M., and Almuneef M. Child abuse and neglect in Saudi Arabia: journey of recognition to implementation of national prevention strategies. Child Abuse and Neglect, 2010, 34:28-33.

16. Morrison JA et al. Emotional development and disorders in young children in the child welfare system. In: Silver JA, Amster BJ, Haecker T, eds. Young children and foster care: $A$ guide for professionals Baltimore, Maryland, Paul H. Brookes, 1999:33-64.

17. Understanding child maltreatment. Fact sheet. Atlanta, Georgia, Centers for Disease Control and Prevention, National Center for Injury Prevention and Control, 2010. 